\title{
APLICAÇÕES AMBIENTAIS DE PERSULFATO: REMEDIAÇÃO DE ÁGUAS SUBTERRÂNEAS E SOLOS CONTAMINADOS
}

\author{
Letícia T. Bertagi ${ }^{a}$, Amanda O. Basilio ${ }^{\mathrm{a}}$ e Patricio Peralta-Zamoraa, ${ }^{\mathrm{a}, *}$

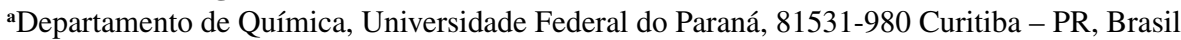

Recebido em 17/03/2021; aceito em 26/04/2021; publicado na web em 19/05/2021

\begin{abstract}
ENVIRONMENTAL APPLICATIONS OF PERSULFATE: REMEDIATION OF CONTAMINATED GROUNDWATER AND SOILS. Environmental remediation represents a major technological challenge due to the complexity of the environmental matrices and the high treatment cost. In recent years, in situ chemical oxidation technologies (ISCO) have shown a good cost/benefit ratio, which has favored their use in the degradation of several relevant environmental pollutants. In this context, persulfate-mediated processes are of relevant importance once persulfate can be activated in situ, promoting the formation of highly oxidative radical species. Persulfate-based treatments have been frequently reported in environmental remediation studies because they guarantee the effective degradation of pollutants without producing significant changes in the remediated matrix. Given these statements, this study aims to discuss the main ways of activating persulfate and the relevant applications in the remediation of groundwater and soils contaminated with resistant organic pollutants.
\end{abstract}

Keywords: persulfate; activation; advanced oxidation process; groundwater remediation; soil remediation.

\section{INTRODUÇÃO}

Nas últimas décadas, a fragilidade do planeta ficou claramente evidenciada, não apenas em razão da notória dilapidação dos recursos naturais, mas principalmente em decorrência do agravamento dos problemas ambientais. Associada ao inadequado gerenciamento de resíduos oriundos dos grandes centros urbanos, do meio industrial e da atividade agrícola, a poluição avança em todos os compartimentos ambientais, comprometendo a qualidade da água, ${ }^{1}$ do solo ${ }^{2}$ e do ar. ${ }^{3}$

Em função dessa realidade, notáveis esforços têm sido dedicados a minimizar o impacto das atividades humanas, instaurando-se políticas, protocolos e práticas que objetivam mitigar o problema na sua fonte (leia-se: redução do consumo, melhoria do transporte público, universalização do saneamento básico, aprimoramento dos processos industriais e das práticas agrícolas, etc.). Entretanto, a adesão de novas práticas é difícil e demorada, o que faz com que a poluição ambiental continue a sua marcha silenciosa, comprometendo a qualidade dos ecossistemas e pondo em risco a saúde pública. ${ }^{4-6}$

Por esses motivos, existe uma grande demanda por técnicas de remediação ambiental que possam ser utilizadas no tratamento de solos e de águas contaminadas. Esse desafio, entretanto, é bastante complexo, não apenas em função da complexidade das matrizes ambientais envolvidas, mas também em decorrência das variadas formas em que se dá a interação entre contaminantes e matrizes contaminadas. Essa dificuldade se mostra ainda maior no estabelecimento de tecnologias orientadas à remediação in situ de sítios contaminados, ${ }^{7,8}$ basicamente em razão do escasso controle dos parâmetros operacionais associados a qualquer tipo de tecnologia e da necessidade de não se alterar significativamente as características do meio remediado. Sendo assim, poucas tecnologias se prestam para o tratamento in situ de solos e águas contaminadas, particularmente quando a contaminação envolve espécies químicas resistentes às técnicas de bioatenuação disponíveis. Dentro desse contexto merecem destaque os processos fundamentados no uso de persulfato, ${ }^{9,10}$ alternativa de tratamento que ganhou notoriedade nos últimos anos, em razão de ser mais segura que processos tradicionais fundamentados no uso de peróxido de hidrogênio.

$\mathrm{O}$ íon persulfato $\left(\mathrm{S}_{2} \mathrm{O}_{8}{ }^{2-}\right)$ é um oxidante forte $\left(\mathrm{E}^{\mathrm{o}} \mathrm{S}_{2} \mathrm{O}_{8}{ }^{2-}-\right.$ $\left.\mathrm{HSO}_{4}{ }^{-}=+2,1 \mathrm{~V}\right)$, de elevada solubilidade em água e boa estabilidade à temperatura ambiente. Em função dessas características, é utilizado desde 1950 como iniciador de processos de polimerização, agente de limpeza de superfícies metálicas, oxidante em processos de síntese orgânica e agente de branqueamento de fibras têxteis, dentre outras aplicações de relevância. Apesar dessas excelentes características, as reações envolvendo persulfato costumam ser bastante lentas, ${ }^{11}$ o que justifica o seu uso como precursor de radical sulfato, de maior poder oxidante $\left(\mathrm{E}^{\mathrm{o}} \mathrm{SO}_{4}{ }^{-} / \mathrm{SO}_{4}{ }^{2-}=+2,6 \mathrm{~V}\right)$. A importância do radical sulfato foi discutida em 1962, em relevante trabalho publicado por House sobre aspectos cinéticos dos processos de oxidação mediados por persulfato. ${ }^{12}$ Entretanto, somente a partir dos anos 2000 o persulfato passou a ser expressivamente avaliado na degradação de poluentes ambientais, sendo particularmente relevantes os trabalhos que vislumbraram um bom potencial de aplicação na remediação in situ de solos e águas subterrâneas contaminadas. ${ }^{13}$

Nos últimos anos, centenas de trabalhos relataram a degradação de poluentes orgânicos resistentes a processos naturais de degradação, ${ }^{14}$ assim como a remediação de solos ${ }^{15}$ e águas contaminadas, ${ }^{16}$ o que permitiu com que o uso de persulfato tenha se consolidado como uma importante tecnologia ISCO (do inglês: in situ chemical oxidation) (ver Figura 1).

\section{ATIVAÇÃO DE PERSULFATO}

A geração de radical sulfato a partir de persulfato, processo comumente denominado de ativação, pode ser viabilizada por diversas formas físicas e químicas, em fase homogênea ou heterogênea, assim como ilustrado na Figura 2.

Dentre os processos físicos, destacam-se aqueles fundamentados em ativação térmica, por radiação UV e ultrassom, nos quais a cisão homolítica da molécula de persulfato leva à formação de dois equivalentes de radical sulfato (Equação 1). 


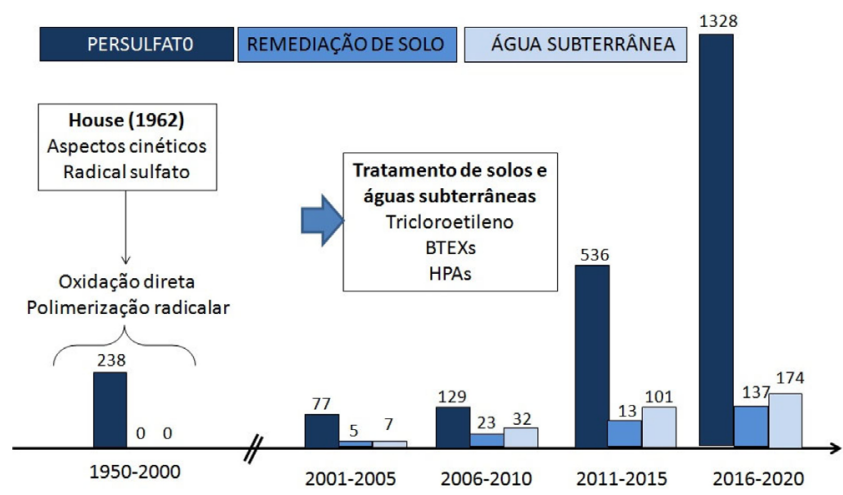

Figura 1. Evolução das publicações relacionadas ao uso de persulfato (Fonte: Periódicos CAPES)

A energia de ativação para essa reação é da ordem de $100 \mathrm{~kJ}$ $\mathrm{mol}^{-1}{ }^{16}$ o que faz com que o processo se mostre mais eficiente com o uso de temperaturas superiores a $60{ }^{\circ} \mathrm{C},{ }^{17}$ comprimentos de onda na região UVC, ${ }^{18}$ e frequências ultrassônicas superiores a $300 \mathrm{kHz}{ }^{19}$

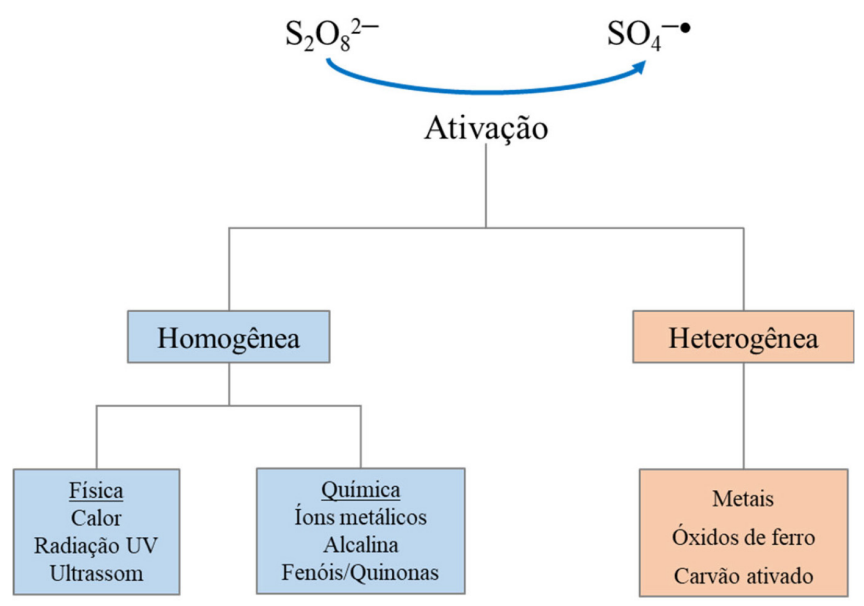

Figura 2. Principais formas de ativação de persulfato

Dos processos químicos em fase homogênea, destaca-se a ativação alcalina, usualmente envolvendo reações em $\mathrm{pH}$ entre $11 \mathrm{e}$ 12. ${ }^{4}$ Nessas condições, a hidrólise do persulfato leva à geração do íon hidroperoxila (Equação 2), que reage com persulfato em uma reação que transfere um elétron, formando radical sulfato e ânion radical superóxido (Equação 3).

$$
\begin{gathered}
\mathrm{S}_{2} \mathrm{O}_{8}{ }^{2-}+\mathrm{H}_{2} \mathrm{O} \rightarrow 2 \mathrm{SO}_{4}{ }^{2-}+\mathrm{HO}_{2}{ }^{-}+\mathrm{H}^{+} \\
\mathrm{S}_{2} \mathrm{O}_{8}{ }^{2-}+\mathrm{HO}_{2} \stackrel{-}{\rightarrow \mathrm{HO}^{-}} \rightarrow \mathrm{SO}_{4}{ }^{2-}+\mathrm{SO}_{4}^{-}+\mathrm{O}_{2}^{-}+\mathrm{H}^{+}
\end{gathered}
$$

Em meio alcalino, espécies fenólicas também podem reduzir o persufato, de acordo com o processo proposto por Ahamad et al. ${ }^{20}$ Em função dessa ativação ser observada em pH 12, mas não em pH 8, sugere-se que a reação necessariamente envolve a formação preliminar de fenolatos (Equação 4). ${ }^{21}$

$$
\mathrm{PhO}^{-}+\mathrm{S}_{2} \mathrm{O}_{8}{ }^{2-} \rightarrow \mathrm{SO}_{4}{ }^{2-}+\mathrm{SO}_{4}^{-\bullet}+\mathrm{PhO}_{\text {ox }}
$$

Íons de metais de transição, como $\mathrm{Fe}, \mathrm{Co}, \mathrm{Mn}, \mathrm{Cu}, \mathrm{Ni}$ e $\mathrm{Zn}$, também permitem a ativação de persulfato em meio homogêneo,,$^{22,23}$ de acordo com a equação genérica apresentada a seguir (Equação 5). Particular importância mostram os processos viabilizados por $\mathrm{Fe}^{2+}$, que apresenta elevada eficiência como ativador, menor toxicidade e baixo custo relativo.

$$
\mathrm{S}_{2} \mathrm{O}_{8}{ }^{2-}+\mathrm{M}^{\mathrm{n}+} \rightarrow \mathrm{M}^{\mathrm{n}+1}+\mathrm{SO}_{4}{ }^{2-}+\mathrm{SO}_{4}^{-}
$$

De forma análoga, ferro metálico ${ }^{24}$ e óxidos de ferro ${ }^{25}$ podem catalisar a decomposição de persulfato, via processos heterogêneos bastante utilizados na remediação ambiental. Em meio ácido, ferro metálico pode formar $\mathrm{Fe}^{2+}$ na presença (Equação 6) ou ausência de oxigênio (Equação 7), o que viabiliza a geração de radical sulfato de acordo com a expressão apresentada na Equação 5.

$$
\begin{aligned}
& 2 \mathrm{Fe}+\mathrm{O}_{2}+2 \mathrm{H}_{2} \mathrm{O} \rightarrow 2 \mathrm{Fe}^{2+}+4 \mathrm{HO}^{-} \\
& 2 \mathrm{Fe}+2 \mathrm{H}_{2} \mathrm{O} \rightarrow 2 \mathrm{Fe}^{2+}+2 \mathrm{HO}^{-}+\mathrm{H}_{2}
\end{aligned}
$$

Embora esse mecanismo seja bem aceito, existem argumentos que apontam para um processo heterogêneo que não envolve a participação de formas solúveis de ferro. Nesse caso, o processo envolve a transição direta de um elétron do $\mathrm{Fe}$ metálico, ou de $\mathrm{Fe}^{2+}$ previamente adsorvido, para a molécula de persulfato, como mostrado na Equação $8 .{ }^{26}$

$$
\mathrm{Fe}(\mathrm{s})+2 \mathrm{~S}_{2} \mathrm{O}_{8}{ }^{2-} \rightarrow \mathrm{Fe}^{2+}+2 \mathrm{SO}_{4}{ }^{2-}+2 \mathrm{SO}_{4}^{-}
$$

A ativação heterogênea de persulfato também pode ser catalisada por óxidos metálicos, sendo particularmente relevante o uso de óxidos e oxi-hidróxidos de ferro, como magnetita, hematita, goethita e ferrihidrita. ${ }^{25}$ Com óxidos que contém apenas Fe (III), admite-se uma reação preliminar que leva à geração de Fe (II) e de radical persulfato (Equação 9), seguida da reação de decomposição que leva à geração de radical sulfato (Equação 10).

$$
\begin{gathered}
\equiv \mathrm{Fe}(\mathrm{III})-\mathrm{OH}+\mathrm{S}_{2} \mathrm{O}_{8}{ }^{2-} \rightarrow \equiv \mathrm{Fe}(\mathrm{II})-\mathrm{OH}+\mathrm{S}_{2} \mathrm{O}_{8}{ }^{-} \\
\equiv \mathrm{Fe}(\mathrm{II})-\mathrm{OH}+\mathrm{S}_{2} \mathrm{O}_{8}{ }^{2-} \rightarrow \equiv \mathrm{Fe}(\mathrm{III})-\mathrm{OH}+\mathrm{SO}_{4}{ }^{2-}+\mathrm{SO}_{4}{ }^{-}
\end{gathered}
$$

De acordo com Wang e Wang, ${ }^{14}$ em processos heterogêneos envolvendo materiais a base de carbono (C), como carvão ativado, nanotubos de carbono e grafeno, a ativação de persulfato se dá pela transferência de elétrons da rede de carbono $\mathrm{sp}^{2}$ ou de grupos funcionais oxigenados, conforme representado na Equação 11.

$$
2 \mathrm{~S}_{2} \mathrm{O}_{8}{ }^{2-}+\mathrm{e}^{-} \rightarrow \mathrm{SO}_{4}^{2-}+2 \mathrm{SO}_{4}^{-}
$$

Entretanto, existem novos argumentos que apontam para reações não radicalares, viabilizadas por grupos que agem como bases de Lewis (ex. $\mathrm{C}=\mathrm{O})^{27}$ ou por lacunas que surgem da reação preliminar entre persulfato e o material carbonáceo. ${ }^{28}$

\section{MECANISMOS DE REAÇÃO}

$\mathrm{O}$ íon persulfato pode reagir diretamente com alguns compostos orgânicos (CO), gerando radical sulfato (Equação 12) e radicais orgânicos (Equação 13) que propagam as reações de degradação. ${ }^{16}$ Entretanto, a principal via de degradação em sistemas ativados envolve a formação preliminar de radical sulfato, agente eletrofílico que pode reagir com moléculas orgânicas por abstração de hidrogênio, adição a duplas ligações ou transferência de elétrons.

$$
\begin{gathered}
\mathrm{S}_{2} \mathrm{O}_{8}^{2-}+\mathrm{CO} \rightarrow \mathrm{SO}_{4}^{2-}+\mathrm{SO}_{4}^{-\bullet}+\mathrm{CO}^{*} \\
\mathrm{~S}_{2} \mathrm{O}_{8}^{2-}+\mathrm{CO} \rightarrow 2 \mathrm{SO}_{4}^{-}+\mathrm{CO}^{-}
\end{gathered}
$$

Em meio aquoso, entretanto, radical sulfato hidrolisa formando radical hidroxila (Equação 14), espécie que pode reagir com 
moléculas orgânicas por abstração de hidrogênio, adição a duplas ligações e substituição eletrofílica. Uma vez que a hidrólise é fortemente favorecida em meio alcalino (Equação 15), admite-se que radical sulfato seja predominante em meio ácido, enquanto radical hidroxila seja predominante em meio alcalino.

$$
\begin{gathered}
\mathrm{SO}_{4}^{-}+\mathrm{H}_{2} \mathrm{O} \rightarrow \mathrm{SO}_{4}^{2-}+\mathrm{H}^{+}+\mathrm{HO}^{-} \\
\mathrm{SO}_{4}^{-}+\mathrm{HO}^{-} \rightarrow \mathrm{SO}_{4}^{2-}+\mathrm{HO}^{-}
\end{gathered}
$$

Embora o uso de agentes sequestrantes de radicais permita evidenciar as espécies radicalares mais ativas no processo de degradação, é seguro afirmar que ambas as formas radicalares participam do processo. Estudos recentes de Yang et al. ${ }^{29}$ entretanto, sugerem que radical hidroxila esteja principalmente envolvido em reações de abstração de hidrogênio e de adição, enquanto radical sulfato participe preferencialmente de reações de transferência envolvendo um elétron, como verificado em estudos de degradação de sulfonamidas. Recentemente, estudos teóricos sobre a degradação de poluentes orgânicos fenólicos por radicais hidroxila e sulfato foram realizados por Mei et al..$^{30}$ Nesses estudos, a reatividade de 19 poluentes fenólicos em solução aquosa foi avaliada por meio da teoria do funcional de densidade, confirmando-se a transferência de um elétron como a principal via de reação do radical sulfato.

Na Figura 3 são ilustradas essas diferenças mecanísticas, tomando fenol como exemplo e antecedentes reportados por Luo et al. ${ }^{31}$

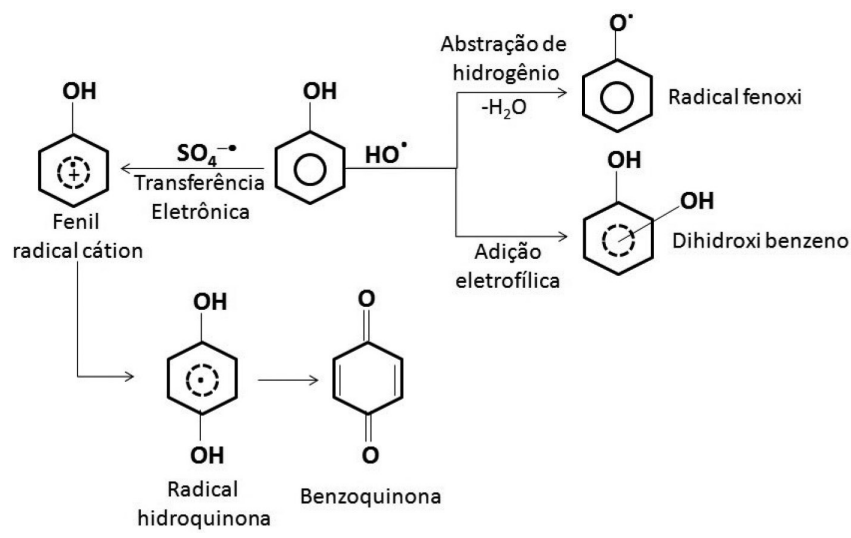

Figura 3. Diferenças mecanísticas observadas nas reações mediadas por radical sulfato e radical hidroxila

\section{REMEDIAÇÃO AMBIENTAL}

Os processos de oxidação química in situ (ISCO) fundamentados no uso do persulfato ganharam visibilidade nos últimos anos, principalmente na remediação de solos contaminados. Nos últimos 5 anos, centenas de trabalhos têm relatado o uso desse tipo de processos no tratamento de solos contaminados por petróleo ${ }^{32}$ e derivados, ${ }^{33}$ hidrocarbonetos policíclicos aromáticos ${ }^{34}$ e pesticidas, ${ }^{35}$ dentre outros poluentes de relevância, usualmente apontando para uma elevada relação custo-benefício.

Por outro lado, muitos trabalhos relatam a degradação de poluentes em solução aquosa, o que possibilitou a publicação de extensos artigos de revisão. No trabalho de Wang e Wang, ${ }^{14}$ por exemplo, discutem-se as principais formas de ativação e salientam-se estudos de degradação de contaminantes de preocupação emergente em escala de bancada e em solução aquosa. Um trabalho similar foi publicado por Ike e colaboradores, ${ }^{11}$ salientando-se a degradação de compostos orgânicos e realizando-se uma análise crítica sobre o emprego dos sistemas de persulfato ativado na remediação ambiental. Apesar desses trabalhos demonstrarem a relevância e o potencial desses sistemas para degradação de contaminantes orgânicos, em ambos os casos os autores destacam a pequena parcela de trabalhos publicados sobre a remediação de águas naturais contaminadas. Dentro desse contexto, destacam-se trabalhos que envolvem a degradação de compostos orgânicos clorados, ${ }^{36}$ herbicidas ${ }^{37}$ e fármacos. ${ }^{38}$

\section{Remediação in situ de águas naturais}

Para facilitar uma avaliação comparativa das diversas formas de ativação de persulfato, restringiremos essa discussão à remediação de apenas um tipo de amostra (águas subterrâneas), levando em consideração somente um conjunto de poluentes (organoclorados). A esse respeito, é relevante salientar que a proteção dos aquíferos subterrâneos deve ser considerada prioritária, em razão de representarem uma importante fonte de água para usos domésticos, agrícolas e industriais, ao mesmo tempo em que se mostram muito vulneráveis à contaminação por ações antrópicas. ${ }^{39}$

Dentro da categoria de poluentes organoclorados destacam pesticidas associados à atividade agrícola e solventes utilizados no meio industrial, sendo que nessa última categoria, também destaca o tricloroetileno (TCE), insumo industrial vastamente utilizado como agente desengraxante. Em razão de vazamentos de tanques de estocagem ou de manejo inapropriado dos resíduos industriais, TCE é praticamente ubíquo em águas subterrâneas, nas quais forma uma fase líquida densa não-aquosa (DNAPL) que se deposita no fundo do aquífero, servindo como estoque permanente para a contaminação da água. ${ }^{40}$

\section{Ativação térmica}

Muitos estudos têm demonstrado a elevada capacidade de degradação de processos fundamentados no uso de persufato ativado termicamente, evidenciando uma correlação positiva entre a eficiência de degradação e a temperatura aplicada. Assim, muitos poluentes ambientais de relevância podem ser eficientemente degradados por processos que envolvem temperaturas superiores a $50{ }^{\circ} \mathrm{C} .{ }^{41}$ Por razões operacionais, o uso de elevadas temperaturas de ativação dificulta a implementação de sistemas de tratamento in situ de águas subterrâneas, o que faz com que a grande maioria dos estudos envolva processos em escala de bancada, visualizando uma aplicação do tipo pump and treat, sistema de tratamento em que a água subterrânea é previamente retirada, para ser tratada de forma ex-situ..$^{42}$

Dentro desse contexto destaca o trabalho de Gu et al. ${ }^{43}$ que avaliou a degradação de 1,1,1-tricloroetano (TCA) em água subterrânea amostrada em um local contaminado, utilizando temperatura de $50{ }^{\circ} \mathrm{C}$ e razão PS:TCA de 50:1, 100:1 e 200:1. Nessas condições a degradação de TCA foi parcial (13 a 27\%), principalmente em razão do consumo improdutivo de persulfato por reação com a matéria orgânica e pelo sequestro de radicais por parte de outros constituintes da matriz (ex. $\mathrm{Cl}^{-}$e $\mathrm{HCO}_{3}^{-}$). Degradações superiores a $95 \%$ foram observadas somente após $8 \mathrm{~h}$ de tratamento, utilizando-se razão PS:TCA de 500:1 e trabalhando-se com uma amostra previamente diluída cerca de 10 vezes.

Mais recentemente, Dominguez e colaboradores ${ }^{44}$ avaliaram a degradação de vários compostos organoclorados extraídos de um aquífero contaminado, utilizando temperaturas entre 30 e $50{ }^{\circ} \mathrm{C}$ e concentrações de persulfato entre 2 e $40 \mathrm{~g} \mathrm{~L}^{-1}$. Nas melhores condições de degradação $\left(40{ }^{\circ} \mathrm{C}\right.$ e $10 \mathrm{~g} \mathrm{~L}^{-1}$ de persulfato) o processo permitiu completa degradação e declorinação de mono, di, tri e tetra-cloro benzeno, além de mineralizações da ordem de $80 \%$, em tratamentos de 168 dias.

De maneira geral, a ativação térmica de persulfato é bastante favorecida em temperaturas superiores a $50{ }^{\circ} \mathrm{C}$, o que dificulta a execução de remediações ambientais praticadas in situ. Dessa forma, 
processos de ativação térmica orientados à remediação de águas subterrâneas envolvem o uso de temperaturas inferiores a $50^{\circ} \mathrm{C}$, o que normalmente obriga ao uso de elevadas concentrações de persulfato. Por outro lado, a ação das formas radicalares que surgem da ativação de persulfato fica bastante comprometida no tratamento de uma matriz que contém agentes sequestrantes de radical, principalmente íons inorgânicos. Dobosy e colaboradores, ${ }^{45}$ por exemplo, realizaram uma interessante comparação entre processos mediados por ferrato $\left(\mathrm{FeO}_{4}{ }^{2-}\right)$, um poderoso agente oxidante $\left(\mathrm{E}^{\mathrm{o}}=+2,2 \mathrm{~V}\right)$, e persulfato ativado termicamente, em relação à degradação de mono e diclorobenzenos. Embora o processo mediado por persulfato tenha sido mais eficiente quando aplicado em solução aquosa, ambos processos se mostraram equivalentes quando aplicados em amostras de águas subterrâneas, basicamente em razão do negativo efeito da presença de sequestrantes, como bicarbonato, cloreto e sulfato, em processos mediados por espécies radicalares.

\section{Ativação alcalina}

Do ponto de vista operacional, a ativação alcalina de persulfato se mostra relativamente simples, o que poderia viabilizar a remediação in situ de águas subterrâneas. Entretanto, o elevado consumo de agente alcalinizante, tipicamente $\mathrm{NaOH}$, e as modificações inseridas pelo seu uso, que podem envolver a mobilização ou a precipitação de íons metálicos, fazem com que essa alternativa de remediação não seja muito estudada.

Liang et al., ${ }^{40}$ por exemplo, avaliaram o efeito do $\mathrm{pH}(4,7 \mathrm{e}$ 9) na degradação de tricloroetileno (TCE) por persulfato (PS), objetivando avaliar a potencialidade do processo na remediação de águas subterrâneas a temperatura ambiente $\left(10-30{ }^{\circ} \mathrm{C}\right)$. Nos testes preliminares, maior eficiência de degradação foi observada em meio neutro ( $\mathrm{pH}$ 7), em decorrência da formação prioritária de radical hidroxila. Embora a geração de radical hidroxila possa ser favorecida em $\mathrm{pH}$ 9, a eficiência de degradação diminui, provavelmente em decorrência do efeito sequestrante causado pelo excesso de radicais.

A ativação alcalina de persulfato também foi avaliada na degradação de hexaclorociclohexano (inseticida) e outros clorobenzenos em águas subterrâneas ${ }^{36}$ utilizando-se concentrações de persulfato entre 42 e $200 \mathrm{mmol} \mathrm{L}^{-1}$ e $\mathrm{NaOH}$ na razão $\mathrm{NaOH}: P S$ de $2: 1$ a $4: 1$. O processo foi monitorado por 25 dias, observando-se uma rápida declorinação preliminar, seguida de eficiente degradação, sem geração de subprodutos aromáticos. Verificou-se, ainda, que as melhores condições de degradação não são necessariamente as que utilizam maiores concentrações de persulfato ou de $\mathrm{NaOH}$, em decorrência do efeito sequestrante exercido pelos excessos de reagente. Trata-se de um resultado que permite prever uma elevada eficiência de degradação em águas subterrâneas que apresentem um efeito tamponante que permita alcançar uma condição de neutralidade, assim como a necessidade de ajustes de $\mathrm{pH}$ em situações em que a adição de persulfato acidifique o meio. É importante ressaltar que o uso de razões molares PS:TCE de 50:1 permitiu a degradação praticamente completa de TCE em tempos de $46 \mathrm{~h}\left(\mathrm{a} 30^{\circ} \mathrm{C}\right)$ e $336 \mathrm{~h}$ $\left(\right.$ a $10{ }^{\circ} \mathrm{C}$ ), o que levou a decomposição de aproximadamente $5 \%$ da concentração inicial de PS. Esse último resultado destaca uma das principais vantagens associada ao uso de PS, que corresponde a uma estabilidade que permite a extensão do tratamento por vários dias.

Finalmente, é relevante salientar um trabalho de remediação realizado em campo (indústria química desativada), envolvendo o tratamento de uma fase líquida densa não-aquosa (DNAPL) contendo solventes orgânicos clorados. ${ }^{46} \mathrm{O}$ aquífero, localizado a $16 \mathrm{~m}$ de profundidade e tendo $20 \mathrm{~m}$ de espessura, continha 1,1-dicloroetano (1,1-DCA), 1,2-dicloroetano (1,2-DCA), 1,1,2-tricloroetano (1,1,2-TCA) e tricloroetileno (TCE), em concentrações da ordem de $3.000,59.000,1.000,900$ e $300 \mu \mathrm{g} \mathrm{L}^{-1}$, respectivamente. O tratamento consistiu em uma etapa de 180 dias em que a fase contaminada foi retirada e tratada com carvão ativado, seguida de uma etapa de 48 dias em que a remediação in situ foi viabilizada pela adição de $\mathrm{NaOH}$ $(1,5 \%)$ e persulfato $(0,05 \%)$. A associação de ambas as técnicas permitiu reduzir significativamente a concentração dos compostos alvo, em cerca de 250 dias de tratamento.

\section{Ativação por formas de ferro}

$\mathrm{O}$ uso de formas solúveis de ferro, principalmente $\mathrm{Fe}$ (II), para a ativação de persulfato é uma das alternativas mais propostas para a remediação in situ de águas subterrâneas, basicamente em razão da sua elevada eficiência de degradação e da relativa simplicidade de aplicação.

Em 2014, Wu et al. ${ }^{47}$ avaliaram a degradação de TCE por persulfato ativado por Fe (II) complexado com ácido cítrico (AC), observando degradação praticamente completa do TCE em tratamentos de $60 \mathrm{~min}$, utilizando proporções PS:Fe(II):AC:TCE de 15:2:1:1 ( $\mathrm{pH} \approx 4)$. Nessas condições foram detectados radical sulfato, radical hidroxila e aníon radical superóxido $\left(\mathrm{O}_{2}{ }^{-}\right)$, dos quais o radical hidroxila foi o mais ativo. Na presença de AC a degradação de TCE se processou com velocidade 50 vezes superior, em relação à ausência de complexante, em razão da complexação evitar a precipitação de $\mathrm{Fe}(\mathrm{III})$, que é rapidamente produzido nas condições utilizadas no estudo. Ânions usualmente presentes em águas subterrâneas $\left(\mathrm{Cl}^{-} \mathrm{e}\right.$ $\mathrm{HCO}_{3}^{-}$) influenciaram significativamente a eficiência do processo, basicamente em razão do sequestro de radicais.

Dentro do contexto da ativação por Fe(II), também se destaca o trabalho de Jiang e colaboradores ${ }^{48}$ que avaliaram a capacidade de um sistema fundamentado no uso de persulfato ativado por íons ferro (II) complexado com cisteína, na degradação de monoclorobenzeno (MCB) em água subterrânea. O processo permitiu elevada eficiência de degradação do composto alvo ( $>90 \%)$ em uma ampla faixa de $\mathrm{pH}$ (2 a 9), principalmente em função da participação de radical hidroxila, que desencadeou uma sequência de reações de declorinação, polihidroxilação, abertura de anel e mineralização. De acordo com os resultados apresentados, a cisteína, além de evitar a precipitação de $\mathrm{Fe}(\mathrm{III})$, favorece a regeneração do $\mathrm{Fe}(\mathrm{II})$, o que também favorece a ativação do persulfato e aumenta a capacidade de degradação do sistema.

Mais recentemente foi avaliada a degradação in situ de TCE em águas subterrâneas, ${ }^{49}$ utilizando-se ativação por Fe(II) complexado por ácido cítrico, na presença de surfactantes. Em geral, o uso de surfactantes favorece a remediação de aquíferos, em razão de aumentar a solubilidade dos contaminantes que fazem parte da fase líquida densa não-aquosa (DNAPL). $\mathrm{O}$ uso do surfactante Tween 80 (polissorbato $80, \mathrm{C}_{64} \mathrm{H}_{124} \mathrm{O}_{26}$ ) permitiu eficiente solubilização de TCE, mas diminuiu a sua degradação, em razão do TCE acumular no núcleo hidrofóbico das micelas, ficando menos disponível para ação dos radicais. Por outro lado, o surfactante compete com o TCE pelos radicais formados, o que fez com que cerca de $30 \%$ do Tween 80 tenha sido degradado no processo. De qualquer forma, admite-se que o uso de surfactantes se mostra vantajoso, podendo fazer parte de rotinas de remediação envolvendo poluentes fortemente adsorvidos.

Um estudo de remediação in situ de águas subterrâneas contaminadas com BTEX e vários hidrocarbonetos clorados, incluindo 1,2,3-tricloropropano (TCP), foi relatado em $2019,{ }^{50}$ envolvendo o uso de persulfato/Fe(II)/ácido cítrico (razão molar 20:5:1). O reagente $\left(6 \mathrm{~m}^{3}\right)$ foi injetado em profundidades de 8 e $15 \mathrm{~m}$, o que provocou um aumento na concentração de hidrocarbonetos na fase aquosa, em razão de dissolução a partir da fase líquida não-aquosa (NAPL). Em um segundo momento, os BTEX foram degradados eficientemente, enquanto a degradação de TCP foi apenas parcial (30-45\%) em 80 dias de tratamento. Esses resultados sugerem que a eficiência do 
tratamento depende mais da concentração e biodegradabilidade dos compostos alvo, do que das características do aquífero. Finalmente, é importante salientar que nesses estudos foi verificada a formação de vários subprodutos clorados, alguns dos quais permanecem por tempos de até 80 dias (ex. 1,2-dicloropropano). ${ }^{50}$ Trata-se de um antecedente que deve ser considerado nos estudos de remediação, em razão de alguns subprodutos poderem ser mais tóxicos do que os compostos de partida.

Em geral, o uso de $\mathrm{Fe}$ (II) restringe bastante a faixa operacional de pH dos processos, em razão da precipitação do $\mathrm{Fe}(\mathrm{III})$ em valores de $\mathrm{pH}$ próximos a 5 levar à formação de oxi(hidróxidos), como goethita, de menor atividade catalítica. Assim, o uso de agentes complexantes é bastante popular nesse tipo de ativação, uma vez que, além de ampliar a faixa de $\mathrm{pH}$, diminui o efeito sequestrante do $\mathrm{Fe}(\mathrm{II})$ em solução, o que aumenta a eficiência de degradação. ${ }^{51,52}$

Por outro lado, algumas propostas de tratamento in situ prescindem da adição de sais de ferro, objetivando aproveitar as formas minerais de ferro naturalmente presentes na água. Chang et al.,$^{53}$ por exemplo, realizaram um estudo em escala piloto para avaliar a remediação de águas subterrâneas contaminadas com TCE, em uma instalação industrial de cerca de $980.000 \mathrm{~m}^{2}$. $\mathrm{O}$ aquífero, a 5-7 $\mathrm{m}$ de profundidade, apresentava uma pluma de contaminação de cerca de $5.200 \mathrm{~m}^{2}$, contendo concentrações de TCE entre 0,04 e $0,384 \mathrm{mg} \mathrm{L}^{-1}$. O tratamento foi viabilizado pela injeção de cerca de $5000 \mathrm{~L}$ de solução aquosa de persulfato $5 \%(\mathrm{~m} / \mathrm{m})$, com vazão de $10 \mathrm{~L} \mathrm{~min}^{-1}$. De acordo com os resultados apresentados, a degradação de TCE foi bastante eficiente em poços dias de tratamento, provavelmente em razão da ativação assistida por formas minerais de ferro presentes no sedimento, em concentrações da ordem de $40.100 \mathrm{mg} \mathrm{kg}^{-1}$. Saliente-se, adicionalmente, que o persulfato persistiu por 14 dias no aquífero, o que pode ser bastante útil quando houver necessidade de prolongar o tratamento.

\section{Considerações finais}

Os trabalhos aqui salientados demonstram a elevada capacidade do persulfato para a degradação de poluentes ambientais em solução aquosa, incluindo espécies organocloradas de difícil degradação natural. Entretanto, existem pelo menos dois aspectos que devem ser levados em consideração para a implementação de tecnologias orientadas para a remediação in situ de águas subterrâneas contaminadas.

Em primeiro lugar, é importante avaliar a presença de substâncias que podem consumir persulfato, sem levar à produção de radicais (ex. matéria orgânica dissolvida), e de ânions inorgânicos que podem agir como agentes sequestrantes de radical (ex. $\mathrm{Cl}^{-}$e $\mathrm{HCO}_{3}^{-}$). Em geral, elevadas concentrações dessas espécies diminuem significativamente a eficiência do processo, o que obriga ao uso de maiores concentrações de persulfato.

Em segundo lugar, é importante considerar o efeito que o tratamento pode provocar na qualidade da água remediada, principalmente do ponto de vista da toxicidade. Com a finalidade de elucidar esse tipo de aspecto, Liang e Wang ${ }^{54}$ avaliaram a toxicidade aguda $\left(\mathrm{LC}_{50}\right)$ das amostras tratadas, utilizando carpas como organismo teste. De acordo com esse estudo, a introdução de persulfato altera o $\mathrm{pH}$ e a salinidade da água, o que pode provocar diversos efeitos deletérios no ecossistema aquático, incluindo elevada letalidade dos bioindicadores, provocada principalmente pelo persulfato. Adicionalmente, estudos realizados por Chang et al. ${ }^{53}$ confirmam o elevado efeito tóxico do persulfato nas comunidades microbianas da água subterrânea, algumas das quais, entretanto, podem se recuperar após o tratamento.

Observações desse tipo justificam a realização de estudos que permitam otimizar a concentração de persulfato, maximizando a sua eficiência e minimizando o seu efeito tóxico, assim como o desenvolvimento de materiais que permitam a liberação controlada de persulfato. Com esse objetivo, Liang e $\mathrm{Chen}^{55}$ propuseram o uso de barras de parafina contendo persulfato sólido, as quais, permitindo a liberação controlada de persulfato por um longo período, representam uma boa alternativa para a remediação in situ de aquíferos contaminados.

Finalmente, é sempre importante considerar que reações de base radicalar são muito complexas, o que pode levar à geração de subprodutos de maior toxicidade do que a dos compostos de partida, como observado na degradação de adoçantes artificiais, ${ }^{56}$ propanolol ${ }^{57}$ e acetominofeno..$^{58}$

Uma ilustração de todas essas considerações é apresentada na Figura 4, na qual se evidencia a ativação de persulfato por formas minerais de ferro (III), o efeito interferente da matéria orgânica (MO) e de ânions inorgânicos, a formação de subprodutos da degradação e a incerteza acerca do efeito do tratamento no ecossistema aquático.

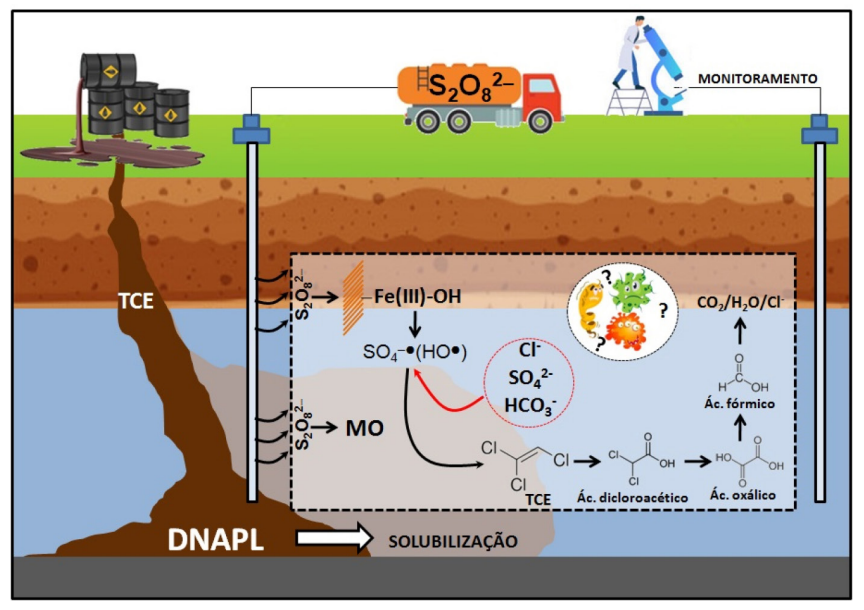

Figura 4. Ilustração das principais interferências encontradas na remediação in situ de águas subterrâneas utilizando-se persulfato, e dos riscos associados ao tratamento

\section{Remediação de solos contaminados}

A oxidação química in situ (ISCO) provou ser uma tecnologia eficiente para a remediação de uma grande variedade de solos contaminados, em diferentes condições hidrogeológicas. ${ }^{59}$ Dentro desse contexto, particular interesse tem sido dedicado a processos de base radicalar, os quais, de maneira geral, permitem a eficiente degradação de contaminantes no subsolo,${ }^{60}$ usualmente formando subprodutos de menor potencial tóxico. ${ }^{6}$

Nos últimos anos, o uso de persulfato em tecnologias ISCO foi bastante difundido, principalmente em razão de vantagens em relação a uso de outros oxidantes, como o reagente de Fenton e o permanganato. Dentre as principais vantagens destaca-se a maior estabilidade do persulfato no solo, o que prolonga o tempo de tratamento, a ampla faixa de $\mathrm{pH}$ em que o processo pode ser aplicado e a menor agressividade do tratamento, principalmente quando comparado com processos em que se utiliza $\mathrm{H}_{2} \mathrm{O}_{2}{ }^{59}$ Admite-se, por exemplo, que o processo Fenton pode gerar um elevado impacto no solo e nas comunidades microbianas, ${ }^{61,62}$ enquanto os efeitos do persulfato são brandos e pouco influenciam os microrganismos nativos do solo. ${ }^{59}$

Como comentado anteriormente, existem muitas alternativas para viabilizar a ativação de persulfato. Entretanto, nem todas são passíveis de aplicação no solo, em razão da complexidade e heterogeneidade dessa matriz, assim como da necessidade de se evitar uma profunda alteração das suas principais características. Dessa forma, as 
aplicações de persulfato envolvem, principalmente, sistemas de ativação mediados por íons metálicos ou óxidos metálicos nativos e, em menor número, sistemas de ativação alcalina e térmica (a baixas temperaturas). A seguir, esses sistemas serão avaliados em reação à remediação de solos contaminados por hidrocarbonetos policíclicos aromáticos (HPAs), poluentes orgânicos persistentes de elevado potencial mutagênico e carcinogênico. ${ }^{34}$

\section{Ativação alcalina}

A utilização de hidróxidos como forma de ativação de persulfato é muito comum em processos que envolvem a degradação de contaminantes orgânicos em águas residuais. Todavia, a aplicação em solos é relativamente recente, sendo frequentemente dificultada pela capacidade tamponante do solo. Nessas circunstâncias, o processo deve envolver o uso de elevadas concentrações de agentes alcalinizantes, o que aumenta o custo e o impacto do processo. ${ }^{15}$

A ativação alcalina de persulfato envolve a formação de radical sulfato, de acordo com as reações representadas nas equações 2 e 3 , e a sua transformação em radical hidroxila, conforme mostrado na Equação 15. De acordo com estudos de Furman et al.. ${ }^{63}$ radical sulfato é predominante em $\mathrm{pH} 7$, ambos radicais coexistem em $\mathrm{pH} 9$ e radical hidroxila é a espécie predominante em $\mathrm{pH} 12$, o que faz com que a reatividade geral do sistema aumente com o aumento da concentração de base. ${ }^{64}$ É relevante salientar, por outro lado, que em valores de $\mathrm{pH}$ superiores a 10 as formas fenólicas presentes no solo tendem a ficar na forma de fenóxido, que também contribui com a formação de radical sulfato (Equação 16). ${ }^{20}$ Assim, a própria complexidade do solo favorece a formação de diferentes espécies reativas que contribuem com a degradação dos contaminantes orgânicos, melhorando a eficiência global dos processos de remediação.

$$
\mathrm{PhO}^{-}+\mathrm{S}_{2} \mathrm{O}_{8}{ }^{2-} \rightarrow \mathrm{SO}_{4}{ }^{2-}+\mathrm{SO}_{4}^{-\bullet}+\mathrm{PhO}_{\text {ox }}
$$

Em 2014, Zhao et al.${ }^{65}$ publicaram um trabalho sobre a degradação de HPAs em um solo industrial contaminado, utilizando persulfato ativado por diversos métodos. A ativação alcalina foi avaliada em escala de bancada, em pH 10, 11 e 12 (ajuste com $\mathrm{NaOH}$ ) e a temperatura ambiente $\left(20{ }^{\circ} \mathrm{C}\right)$, por tempos de até $72 \mathrm{~h}$. Nessas condições, o maior consumo de persulfato foi verificado em pH 11. Entretanto, a maior capacidade de degradação foi observada em pH 12 (aproximadamente $70 \%$ ), principalmente graças à participação de radical superóxido, que surge da reação entre persulfato e íon hidroperoxila (Equação 3).

Mais recentemente, Lominchar et al. ${ }^{64}$ realizaram um estudo de remediação de um solo argiloso artificialmente contaminado com HPAs (fenantreno, antraceno, pireno e benzo[a]pireno), utilizando persulfato, ativação alcalina $(\mathrm{NaOH})$ e biosurfactante (VeruSol-3). Após 3 meses de envelhecimento, o solo fortificado (45 g) foi colocado em uma coluna $(12 \times 3 \mathrm{~cm})$ foi continuamente adicionado de uma mistura aquosa contendo persulfato $\left(210 \mathrm{mmol} \mathrm{L}^{-1}\right), \mathrm{NaOH}$ (840 $\left.\mathrm{mmol} \mathrm{L}^{-1}\right)$ e biosurfactante $\left(15 \mathrm{~g} \mathrm{~L}^{-1}\right)$, calculando-se um tempo de retenção da ordem de $20 \mathrm{~h}$. Na ausência de surfactante, cerca de $30 \%$ da carga inicial de HPAs permaneceu no solo, fortemente adsorvida. Na presença de surfactante a remoção e a degradação foram praticamente completas, em tratamentos de 25 dias.

Embora a ativação alcalina permita elevada eficiência de degradação, é importante destacar que a complexidade dos solos dificulta o entendimento dos mecanismos envolvidos no processo de ativação, assim como dos efeitos negativos que o tratamento pode trazer à saúde do solo. ${ }^{13}$

Ativação térmica

A ativação por calor é eficiente e relativamente simples quando aplicada em sistemas aquosos. No solo, as dificuldades técnicas são maiores, o que diminui drasticamente a sua aplicabilidade.

Em função das dificuldades encontradas na ativação térmica aplicada in situ, grande parte dos trabalhos que objetivam avaliar a potencialidade do processo na remediação de solos envolvem estudos em escala de bancada, muitas vezes utilizando o solo na forma de suspensão aquosa. Ranc et al. ${ }^{66}$ por exemplo, avaliaram duas formas de ativação em estudos de remediação envolvendo um solo com um antigo histórico de contaminação por HPAs. No primeiro sistema, o solo foi pré-aquecido a temperaturas de 60 e $90{ }^{\circ} \mathrm{C}$ por uma semana, sendo posteriormente adicionado de uma solução aquosa de persulfato. No segundo sistema, a adição de persulfato e o aquecimento a $60{ }^{\circ} \mathrm{C}$ se deram simultaneamente, por um período de uma semana. Os resultados indicam que o aquecimento prévio favorece a disponibilidade dos HPAs (dessorção térmica), o que permitiu reduzir de 1.133 a $863\left(60{ }^{\circ} \mathrm{C}\right)$ e $595\left(90{ }^{\circ} \mathrm{C}\right) \mathrm{mg} \mathrm{kg}^{-1} \mathrm{o}$ somatório da concentração dos 16 HPAS considerados prioritários, em uma semana de tratamento. Por outro lado, o aquecimento durante a oxidação com persulfato favorece a cinética do processo, o que permitiu a redução do teor de HPAs totais a $445 \mathrm{mg} \mathrm{kg}^{-1}$, em tratamentos de uma semana a $60^{\circ} \mathrm{C}$.

Intuitivamente se entende que maiores temperaturas induzem uma maior formação de radicais, o que favorece o processo de degradação. Por outro lado, muitos estudos demonstram a elevada eficiência do processo na degradação de poluentes ambientais de todo tipo, ${ }^{40,59,67-69}$ mas sempre em escala de bancada e em temperaturas sempre superiores a $50^{\circ} \mathrm{C}$. É importante mencionar, entretanto, que se estima que temperaturas superiores a $40{ }^{\circ} \mathrm{C}$ podem causar distúrbios no sistema do solo, ${ }^{59} \mathrm{o}$ que aconselha o uso de menores temperaturas de ativação. Assim, embora a ativação de persulfato seja sacrificada em baixas temperaturas, existem vários relatos de processos de remediação aplicados em temperaturas próximas à do ambiente (20 a $30{ }^{\circ} \mathrm{C}$ ), como boa eficiência de degradação. ${ }^{70,71}$

Alguns estudos sugerem temperaturas de ativação em torno de $40{ }^{\circ} \mathrm{C}$ para aplicações em campo, de maneira a se diminuir o custo da operação e a facilitar a redução da temperatura ao final do tratamento. ${ }^{72}$ Todavia, uma das dificuldades de se utilizar a ativação térmica em solos está justamente na capacidade de se manter a temperatura necessária além da superfície. Em recente trabalho, Head e colaboradores ${ }^{73}$ relataram o uso de aquecimento por resistência elétrica para ativação in situ de persulfato em grandes extensões de solo, objetivando encontrar uma maneira de manter a temperatura constante com o aumento da profundidade e avaliar a entrega de persulfato em camadas mais profundas do solo. Os resultados indicaram que a temperatura atingiu o estado estacionário somente após 104 dias de remediação e que a temperatura alvo $\left(40^{\circ} \mathrm{C}\right)$ não foi alcançada em todos os pontos de coleta selecionados. Trata-se de um problema que deve ser superado para aumentar a aplicabilidade desse sistema de ativação.

Existem relatos de ativação térmica viabilizada pela injeção de vapor. ${ }^{74}$ Entretanto, o sistema mostra dificuldades associadas à distribuição irregular do vapor, principalmente em solos de permeabilidade limitada, ao mesmo tempo em que oferece riscos associados à dispersão de fluidos quentes no ambiente subterrâneo. ${ }^{73}$

\section{Ativação por íons metálicos e óxidos minerais}

A procura por métodos de ativação minimamente invasivos tem sido o grande desafio enfrentado para consolidar o uso de persulfato em sistema de tratamento in situ de solos. Dentro desse contexto destaca o uso de íons metálicos, principalmente $\mathrm{Fe}^{2+}$, que permite a ativação de persulfato de acordo com a reação apresentada na Equação 17, que ocorre de forma análoga em águas e solos.

$$
\mathrm{Fe}^{2+}+\mathrm{S}_{2} \mathrm{O}_{8}{ }^{2-} \rightarrow \mathrm{Fe}^{3+}+\mathrm{SO}_{4}{ }^{2-}+\mathrm{SO}_{4} \cdot
$$


Embora bastante eficiente na degradação de poluentes resistentes, incluindo HPAs, ${ }^{35,75-77}$ o uso de formas solúveis de ferro apresenta alguns inconvenientes, dentre os que destacam o rápido consumo de ferro solúvel, o efeito sequestrante de radicais exercido por um excesso de formas solúveis de ferro e a limitada faixa operacional de $\mathrm{pH}$, em razão da precipitação de ferro em valores de $\mathrm{pH}$ próximos à neutralidade. ${ }^{78}$ Em função dessas limitações, ênfase tem sido dada ao uso de formas minerais nativas do solo, particularmente óxidos de ferro como goethita e hematita. ${ }^{34,79}$

Os processos redox que envolvem óxidos de ferro (Equações $9 \mathrm{e}$ 10) são análogos às reações em solução, apresentando, entretanto, as peculiaridades dos processos de caráter heterogêneo. ${ }^{21}$ Nos processos mediados por formas minerais de ferro se espera um mecanismo de ativação heterogêneo, como o representado na Figura 5. Entretanto, a eficiência desse mecanismo depende da estrutura da forma mineral, incluindo características como forma cristalina, área superficial, concentração e estado de oxidação do ferro. ${ }^{80} \mathrm{Em}$ alguns casos, as estruturas cristalinas são fechadas (ex. hematita), o que dificulta o acesso aos sítios de reação, enquanto em outros casos, a estrutura amorfa do óxido (ex. ferrihidrita) facilita a lixiviação de ferro, principalmente em meio ácido, o que favorece processos de ativação homogêneos.

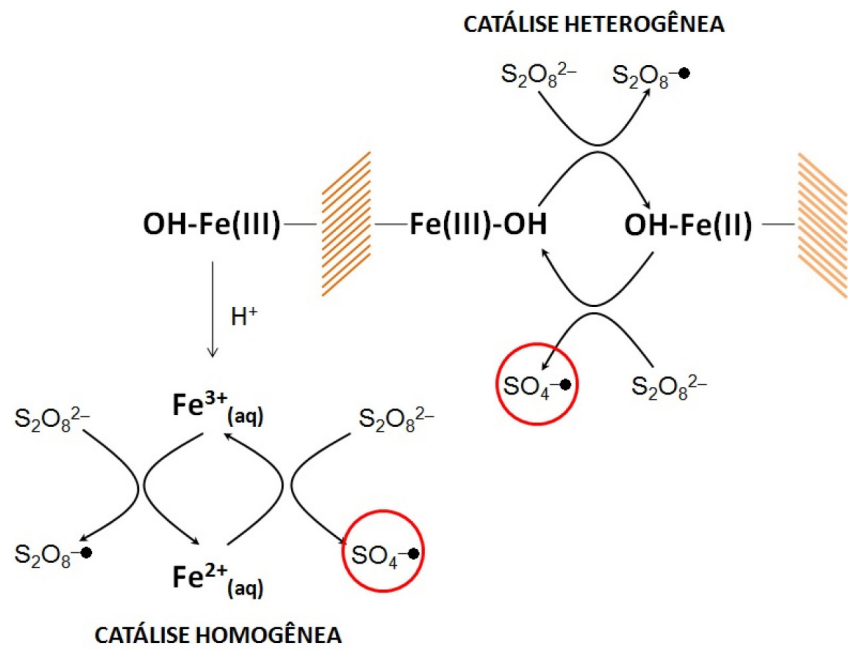

Figura 5. Representação das ativações hetero e homogênea de persulfato em processos mediados por óxidos de ferro

De todos os óxidos minerais de ferro, a goethita destaca como um excelente agente ativador de persulfato, em razão de apresentar uma estrutura cristalina acessível para a catálise heterogênea, ao mesmo tempo em que pode gerar formas solúveis de ferro, o que favorece a catálise homogênea. Assim, goethita apresenta elevada capacidade de ativação em meio ácido, neutro e básico. ${ }^{81}$

A ativação de persulfato por óxidos de ferro nativos se mostra particularmente relevante no Brasil, que apresenta uma grande proporção de latossolos e argissolos com variadas concentrações de ferro mineral, em função da presença de óxidos amorfos (ex. ferrihidrita) e cristalinos (ex. goethita, hematita e magnetita) ${ }^{82} \mathrm{~A}$ presença dessas formas minerais de ferro viabiliza a ativação de persulfato em condições físico-químicas naturais do solo, o que normalmente evita graves perturbações. ${ }^{83}$

Em 2012, Usman e colaboradore ${ }^{78}$ avaliaram a degradação de HPAs em escala de bancada, utilizando ativação de persulfato por magnetita. Estudos preliminares, envolvendo um substrato modelo (9-fluorenona) em uma matriz de areia e processos aplicados em $\mathrm{pH}$ próximos à neutralidade, mostraram eficiente degradação do sistema persulfato/magnetita, o que permitiu remoções de $90 \%$ e mais do que
99\% em tratamento de 48 h e uma semana, respectivamente. Nessas condições, o uso de ferro (II) solúvel levou a degradações muito próximas às observadas na presença isolada de persulfato (20-25\%), em razão de precipitação e formação de óxidos de baixa atividade catalítica. Em um segundo estudo os 16 HPAs prioritários foram previamente extraídos do solo, colocados em areia e tratados pelo sistema persulfato/magnetita, observando-se eficiente degradação, principalmente dos HPAs mais leves. Finalmente, o processo foi aplicado em amostras de solo, observando-se uma degradação inexpressiva dos HPAs, provavelmente em decorrência da baixa disponibilidade dos HPAs e do efeito sequestrante de radicais exercido pela matéria orgânica e pela própria superfície dos minerais.

Mais recentemente, Usman et al. ${ }^{84}$ relataram a degradação de hidrocarbonetos derivados de petróleo em sedimentos de regiões portuárias, utilizando persulfato/magnetita e processos em escala de bancada. O processo permitiu substancial degradação do teor de hidrocarbonetos, monitorados por CG-FID e integrando-se os sinais registrados entre n-decano $\left(\mathrm{C}_{10} \mathrm{H}_{22}\right)$ e n-tetracontano $\left(\mathrm{C}_{40} \mathrm{H}_{82}\right)$, em tratamentos de uma semana. Novamente, a eficiência de processos ativados por ferro solúvel foi muita baixa, em razão de precipitação nas condições de neutralidade em que o estudo foi realizado. De acordo com os autores, nenhum problema associado à disponibilidade dos hidrocarbonetos foi observado, o que demonstra que o processo de degradação não depende exclusivamente da natureza dos poluentes, mas também da natureza da matriz em que estão imersos.

Nos últimos anos, muitos trabalhos têm relatado a ativação de persulfato por ferro zero-valente (FeZV), que pode agir como uma fonte contínua de $\mathrm{Fe}^{2+}$ (Equação 18) ou participar de processos heterogêneos que transferem elétrons diretamente ao persulfato, gerando radical sulfato (Equação 19)..$^{85}$

$$
\begin{gathered}
\mathrm{Fe}_{(\mathrm{s})}^{0}+\mathrm{S}_{2} \mathrm{O}_{8}{ }^{2-} \rightarrow \mathrm{Fe}^{2+}+2 \mathrm{SO}_{4}{ }^{2-} \\
\mathrm{Fe}^{0}{ }_{(\mathrm{s})}+2 \mathrm{~S}_{2} \mathrm{O}_{8}{ }^{2-} \rightarrow \mathrm{Fe}^{2+}+2 \mathrm{SO}_{4}{ }^{2-}+2 \mathrm{SO}_{4}{ }^{-}
\end{gathered}
$$

Dentre outras aplicações relevantes destaca a remediação in situ e em escala piloto de um solo contaminado por HPAs, utilizando persulfato e FeZV de diversos tipos. Após 104 dias de tratamento, degradações de $69 \%$ e $82 \%$ foram observadas na presença de catalisadores macrométricos e nanoestruturados, respectivamente, o que demonstra o favorável efeito da área superficial do catalisador na sua reatividade frente ao persulfato. ${ }^{85}$ Em estudo similar, Peluffo et al. ${ }^{34}$ demonstraram a maior eficiência de degradação de processos fundamentados no uso de FeZV, em relação a processos catalisados por formas solúveis de ferro (II e III), basicamente em razão do FeZV permitir a lenta liberação de $\mathrm{Fe}^{2+}$, que catalisa a decomposição de persulfato sem mostrar relevante efeito sequestrante de radicais.

\section{Considerações finais}

O tratamento de solos é sempre um desafio de grandes proporções, não apenas em razão de algumas características do solo comandarem a dinâmica dos poluentes, mas também em função dessas características influenciarem a formação e a persistência dos radicais e, portanto, a eficiência do processo de degradação. ${ }^{75}$ Dentro desse contexto destacam-se características físicas, como textura e porosidade, químicas, como pH e teor de matéria orgânica e, ainda, biológicas, relacionadas com a atividade microbiana do solo. Embora todas essas características sejam relevantes, estima-se que o teor de matéria orgânica (MO) seja particularmente importante em sistemas ISCO fundamentados no uso de persulfato, em razão da MO consumir oxidante em reações paralelas que não conduzem a formação de radicais e, principalmente, em razão da $\mathrm{MO}$ agir como eficiente sequestrante de radicais, o que inibe a degradação dos contaminantesalvo. Este tipo de interferência foi confirmado por Devi et al., ${ }^{13} \mathrm{em}$ 
estudos envolvendo ácido húmico como modelo de MO do solo. De acordo com observações de Fang et al. ${ }^{70}$ o sequestro de radicais pela MO do solo pode levar à formação de radicais alquílicos $\left(\mathrm{R}^{\bigotimes}\right)$, que podem viabilizar a degradação redutiva de alguns compostos, como organoclorados. Assim, a degradação oxidativa associada a radicais sulfato e hidroxila ficaria reduzida unicamente a solos subsuperficiais com baixo teor de MO.

Em função dessas peculiaridades, o tratamento de solos diferentes deverá prever uma abordagem também diferente, o que faz com que dificilmente possa se criar uma fórmula universal para tratamento de qualquer tipo de solo.

De maneira geral, processos de oxidação química podem introduzir alterações drásticas em algumas propriedades físicoquímicas (ex. pH, capacidade de troca cationnica, condutividade elétrica e teor de carbono orgânico) e microbiológicas do solo, o que pode alterar a finalidade de uso da área tratada. Dessa forma, o tratamento deve ser suficientemente vigoroso, como para degradar a carga de poluentes, e adequadamente brando, para garantir a integridade do solo.

De acordo com muitos relatos, o uso de persulfato provoca baixo impacto no solo tratado, principalmente quando comparado a processos fundamentados no uso de peróxido de hidrogênio e permanganato de potássio. De acordo com observações de Chen et al. ${ }^{59}$ por exemplo, o tratamento com persulfato pode decompor menos de $15 \%$ da matéria orgânica do solo, o que o caracteriza como um método relativamente brando. Entretanto, outros estudos relatam que o uso de persulfato pode causar efeitos diversos no equilíbrio do solo, ${ }^{86} \mathrm{em}$ decorrência de mudanças no $\mathrm{pH}$ e no teor de MO, e da solubilização de espécies estáveis, como sulfetos, o que pode induzir a mobilização de íons de metais pesados. ${ }^{87}$

Com relação ao $\mathrm{pH}$, observa-se que a adição de persulfato pode ultrapassar a capacidade tamponante do solo, o que gera acidificação, principalmente quando se utilizam sistemas de múltiplas adições. Nessas condições, observa-se um significativo aumento na salinidade e condutividade dos microcosmos, ${ }^{15}$ o que pode afetar negativamente algumas comunidades microbianas. Embora estudos sobre o impacto do persulfato no solo sejam escassos, vários relatos confirmam efeitos negativos nos microrganismos nativos, incluindo perda de diversidade microbiana. ${ }^{88,89}$ Por outro lado, estima-se que o uso de doses moderadas de persulfato pode ser estrategicamente interessante, em função de permitir a adaptação da comunidade microbiana. De acordo com estudos de Gou et al., ${ }^{88}$ a degradação da MO leva à geração de espécies de baixa massa molar que podem ser utilizados como nutrientes pela comunidade microbiana, o que pode permitir a sua recuperação durante o tratamento.

Como visto, existem argumentos discrepantes em relação ao efeito do persulfato no ambiente tratado. Entretanto, a elevada estabilidade do persulfato faz com que a sua permanência no solo seja maior do que qualquer outro agente oxidante, o que evita a necessidade do uso de altas concentrações ou de sistemas de adições sucessivas e representa a sua maior vantagem. De qualquer forma, para que essa vantagem seja efetivamente aproveitada, é necessário encontrar um método de ativação minimamente prejudicial, que catalise a decomposição do persulfato e que não altere profundamente as principais características do solo. Desse ponto de vista, o uso de formas minerais nativas do solo provavelmente seja a melhor alternativa.

\section{CONSIDERAÇÕES FINAIS}

O tratamento in situ de solos e de águas contaminadas representa um grande desafio tecnológico, em razão da necessidade de se garantir a efetiva degradação dos poluentes, sem provocar substancial modificação na matriz remediada. Dentre os poucos processos que se ajustam a essa necessidade, destacam-se os mediados por persulfato, agente químico que pode ser ativado por diversos processos, o que leva à geração de radicais fortemente oxidantes.

Embora exista uma grande variedade de formas de ativação de persulfato, são poucas as que podem ser aplicadas em solos e águas contaminadas com uma boa relação custo/benefício. Adicionalmente, o método deve ser ajustado, não apenas em relação à natureza química do conjunto de poluentes, mas também às características físicoquímicas da matriz em tratamento. Por esses motivos, não existe uma receita universal para o tratamento de solos e águas contaminadas, o que obriga a uma avaliação detalhada, caso a caso.

Embora o desafio seja complexo, muitos trabalhos relatam uma degradação eficiente de poluentes ambientais resistentes à degradação natural em águas e solos, com relativamente poucos efeitos colaterais nas propriedades da matriz tratada. Trata-se de uma característica que tem popularizado o uso de persulfato em estudos de remediação ambiental, substituindo outras tecnologias mais agressivas.

\section{REFERÊNCIAS}

1. Wilkinson, J.; Hooda, P. S.; Barker, J.; Barton, S.; Swinden, J.; Environ. Pollut. 2017, 231, 954.

2. Paz-Ferreiro, J.; Gascó, G.; Méndez, A.; Reichman, S. M.; Int. J. Environ. Res. Public Health 2018, 15, 1657.

3. Nielsen, T.; Jørgensen, H. E.; Larsen, J. C.; Poulsen, M.; Sci. Total Environ. 1996, 189-190, 41.

4. Schwarzenbach, R. P.; Egli, T.; Hofstetter, T. B.; Von Gunten, U.; Wehrli, B.; Annu. Rev. Environ. Resour. 2010, 35, 109.

5. Manisalidis, I.; Stavropoulou, E.; Stavropoulos, A.; Bezirtzoglou, E.; Front. Public Heal. 2020, 8.

6. Steffan, J. J.; Brevik, E. C.; Burgess, L. C.; Cerdà, A.; Eur. J. Soil Sci. 2018, 69, 159.

7. Song, B.; Zeng, G.; Gong, J.; Liang, J.; Xu, P.; Liu, Z.; Zhang, Y.; Zhang, C.; Cheng, M.; Liu, Y.; Ye, S.; Yi, H.; Ren, X.; Environ. Int. 2017, 105, 43.

8. Suthersan, S.; McDonough, J.; Schnobrich, M.; Divine, C.; Groundwater Monit. Rem. 2017, 37, 17.

9. Yang, Z. H.; Verpoort, F.; Dong, C. Di; Chen, C. W.; Chen, S.; Kao, C. M.; Process Saf. Environ. Prot. 2020, 138, 18.

10. Chen, K.-F.; Chang, Y.-C.; Chiou, W.-T.; J. Chem. Technol. Biotechnol. 2015, 91,1877 .

11. Ike, I. A.; Linden, K. G.; Orbell, J. D.; Duke, M.; Chem. Eng. J. 2018, 338,651 .

12. House, D. A.; Chem. Rev. 1962, 62, 183.

13. Devi, P.; Das, U.; Dalai, A. K.; Sci. Total Environ. 2016, 571, 643.

14. Wang, J.; Wang, S.; Chem. Eng. J. 2018, 334, 1502.

15. Zhou, Z.; Liu, X.; Sun, K.; Lin, C.; Ma, J.; He, M.; Ouyang, W.; Chem. Eng. J. 2019, 372, 836.

16. Matzek, L. W.; Carter, K. E.; Chemosphere 2016, 151, 178.

17. Shi, H.; Zhou, G.; Liu, Y.; Fu, Y.; Wang, H.; Wu, P.; RSC Adv. 2019, 9, 31370.

18. Norzaee, S.; Bazrafshan, E.; Djahed, B.; Mostafapour, F. K.; Khaksefidi, R.; Sci. World J. 2017, 2017.

19. Yang, L.; Xue, J.; He, L.; Wu, L.; Ma, Y.; Chen, H.; Li, H.; Peng, P.; Zhang, Z.; Chem. Eng. J. 2019, 378, 122146.

20. Ahmad, M.; Teel, A. L.; Watts, R. J.; Environ. Sci. Technol. 2013, 47, 5864.

21. Cai, T.; Liu, Y.; Wang, L.; Dong, W.; Chen, H.; Zeng, W.; Xia, X.; Zeng, G.; Chem. Eng. J. 2019, 375, 122070.

22. Xiao, S.; Cheng, M.; Zhong, H.; Liu, Z.; Liu, Y.; Yang, X.; Liang, Q.; Chem. Eng. J. 2020, 384, 123265.

23. Graça, C. A. L.; Velosa, A. C. de; Teixeira, A. C. S. C.; Catal. Today 2017, 280,80 . 
24. Graça, C. A. L.; Fugita, L. T. N.; Velosa, A. C. de; Teixeira, A. C. S. C. Environ. Sci. Pollut. Res. 2018, 25, 5474.

25. Karim, A. V.; Jiao, Y.; Zhou, M.; Nidheesh, P. V.; Chemosphere 2021, 265, 129057

26. Oh, S. Y.; Kang, S. G.; Chiu, P. C.; Sci. Total Environ. 2010, 408, 3464

27. Jiang, L.; Zhang, Y.; Zhou, M.; Liang, L.; Li, K.; J. Hazard. Mater. 2018, 358, 53.

28. Wu, Y.; Guo, J.; Han, Y.; Zhu, J.; Zhou, L.; Lan, Y.; Chemosphere 2018 , 200, 373.

29. Yang, H.; Zhuang, S.; Hu, Q.; Hu, L.; Yang, L.; Au, C.; Yi, B.; Chem. Eng. J. 2018, 339, 32.

30. Mei, Q.; Sun, J.; Han, D.; Wei, B.; An, Z.; Wang, X.; Xie, J.; Zhan, J.; He, M.; Chem. Eng. J. 2019, 373, 668.

31. Luo, S.; Wei, Z.; Dionysiou, D. D.; Spinney, R.; Hu, W. P.; Chai, L.; Yang, Z.; Ye, T.; Xiao, R.; Chem. Eng. J. 2017, 327, 1056.

32. Li, Y. T.; Li, D.; Lai, L. J.; Li, Y. H.; Chemosphere 2020, 238, 124657.

33. Pardo, F.; Rosas, J.; Santos, A.; Romero, A.; Water, Air Soil Pollut. 2015, $226,1$.

34. Peluffo, M.; Pardo, F.; Santos, A.; Romero, A.; Sci. Total Environ. 2016, 563-564, 649 .

35. Kan, H.; Wang, T.; Yu, J.; Qu, G.; Zhang, P.; Jia, H.; Sun, H.; J. Hazard. Mater. 2021, 401, 123361.

36. Santos, A.; Fernandez, J.; Rodriguez, S.; Dominguez, C. M.; Lominchar, M. A.; Lorenzo, D.; Romero, A.; Sci. Total Environ. 2018, 615, 1070.

37. Ji, Y.; Dong, C.; Kong, D.; Lu, J.; Zhou, Q.; Chem. Eng. J. 2015, 263, 45.

38. Cai, S.; Hu, X.; Lu, D.; Zhang, L.; Jiang, C.; Cai, T.; Sci. Total Environ. 2021, 762, 143092.

39. Machiwal, D.; Jha, M. K.; Singh, V. P.; Mohan, C.; Earth-Sci. Rev. 2018, 185,901

40. Liang, C.; Wang, Z. S.; Bruell, C. J.; Chemosphere 2007, 66, 106.

41. Zhou, Y.; Xiang, Y.; He, Y.; Yang, Y.; Zhang, J.; Luo, L.; Peng, H.; Dai, C.; Zhu, F.; Tang, L.; J. Hazard. Mater. 2018, 359, 396.

42. Boal, A. K.; Rhodes, C.; Garcia, S.; Groundwater Monit. Rem. 2015, 35, 93.

43. Gu, X.; Lu, S.; Li, L.; Qiu, Z.; Sui, Q.; Lin, K.; Luo, Q.; Ind. Eng. Chem. Res. 2011, 50, 11029.

44. Dominguez, C. M.; Romero, A.; Lorenzo, D.; Santos, A.; J. Environ. Manage. 2020, 261, 110240.

45. Dobosy, P.; Vizsolyi, C. É.; Varga, I.; Varga, J.; Láng, G.; Záray, G.; Microchem. J. 2018, 136, 61.

46. Xie, T.; Dang, Z.; Zhang, J.; Zhang, Q.; Zhang, R.-H.; Liao, C.-J.; Lu, G.-N.; RSC Adv. 2021, 11, 4237.

47. Wu, X.; Gu, X.; Lu, S.; Xu, M.; Zang, X.; Miao, Z.; Qiu, Z.; Sui, Q.; Chem. Eng. J. 2014, 255, 585 .

48. Jiang, F.; Li, Y.; Zhou, W.; Yang, Z.; Ning, Y.; Liu, D.; Tang, Z.; Yang, S.; Huang, H.; Wang, G.; Chem. Eng. J. 2020, 387, 124048.

49. Sun, Y.; Li, M.; Gu, X.; Danish, M.; Shan, A.; Ali, M.; Qiu, Z.; Sui, Q.; Lyu, S.; J. Hazard. Mater. 2021, 407, 124814.

50. Li, H.; Han, Z.; Qian, Y.; Kong, X.; Wang, P.; Int. J. Environ. Res. Public Health 2019, 16, 2752.

51. Liang, C.; Liang, C. P.; Chen, C. C.; J. Contam. Hydrol. 2009, 106, 173.

52. Han, D.; Wan, J.; Ma, Y.; Wang, Y.; Huang, M.; Chen, Y.; Li, D.; Guan, Z.; Li, Y.; Chem. Eng. J. 2014, 256, 316.

53. Chang, Y.-C.; Chen, T.-Y.; Tsai, Y.-P.; Chen, K.-F.; RSC Adv. 2018, 8 , 2433

54. Liang, C.; Wang, C. W.; Chemosphere 2013, 93, 2711.

55. Liang, C.; Chen, C.-Y.; Ind. Eng. Chem. Res. 2017, 56, 5271

56. Fu, Y.; Li, S.; Shi, Y.; Geng, J.; Li, J.; Wu, G.; Xu, K.; Ren, H.; Water Res. 2019, 167, 115102.

57. Yang, Y.; Cao, Y.; Jiang, J.; Lu, X.; Ma, J.; Pang, S.; Li, J.; Liu, Y.; Zhou, Y.; Guan, C.; Water Res. 2019, 149, 543.
58. Li, B.; Ma, X.; Deng, J.; Li, Q.; Chen, W.; Li, G.; Chen, G.; Wang, J.; Sci. Total Environ. 2020, 723, 137993.

59. Chen, L.; Hu, X.; Cai, T.; Yang, Y.; Zhao, R.; Liu, C.; Li, A.; Jiang, C.; Chem. Eng. J. 2019, 369, 344

60. Besha, A. T.; Bekele, D. N.; Naidu, R.; Chadalavada, S.; Environ. Technol. Innovation 2018, 9, 303.

61. Cheng, M.; Zeng, G.; Huang, D.; Lai, C.; Xu, P.; Zhang, C.; Liu, Y.; Chem. Eng. J. 2016, 284, 582

62. Lin, H.; Li, Y.; Mao, X.; Zhang, H.; J. Taiwan Inst. Chem. Eng. 2016 $65,390$.

63. Furman, O. S.; Teel, A. L.; Ahmad, M.; Merker, M. C.; Watts, R. J.; J. Environ. Eng. 2011, 137, 241.

64. Lominchar, M. A.; Santos, A.; de Miguel, E.; Romero, A.; Sci. Total Environ. 2018, 622-623, 41.

65. Zhao, D.; Liao, X.; Yan, X.; Huling, S. G.; Chai, T.; Tao, H.; J. Hazard. Mater. 2013, 254-255, 228

66. Ranc, B.; Faure, P.; Croze, V.; Lorgeoux, C.; Simonnot, M. O.; Environ. Sci. Pollut. Res. 2017, 24, 11265

67. Bougie, S.; Dubé, J. S.; J. Environ. Eng. Sci. 2007, 6, 397.

68. Liang, C. J.; Bruell, C. J.; Marley, M. C.; Sperry, K. L.; Soil Sediment Contam. 2003, 12, 207

69. Zhu, C.; Wang, D.; Zhu, F.; Liu, S.; Fang, G.; Gao, J.; Zhou, D.; J. Hazard. Mater. 2021, 402, 123557

70. Fang, G.; Chen, X.; Wu, W.; Liu, C.; Dionysiou, D. D.; Fan, T.; Wang, Y.; Zhu, C.; Zhou, D.; Environ. Sci. Technol. 2018, 52, 14352.

71. Ferreira, I. D.; Prieto, T.; Freitas, J. G.; Thomson, N. R.; Nantes, I. L.; Bechara, E. J. H.; Water. Air. Soil Pollut. 2017, 228, 146

72. Peng, L.; Deng, D.; Guan, M.; Fang, X.; Zhu, Q.; Sep. Purif. Technol. 2015, 150, 215

73. Head, N. A.; Gerhard, J. I.; Inglis, A. M.; Nunez Garcia, A.; Chowdhury, A. I. A.; Reynolds, D. A.; de Boer, C. V.; Sidebottom, A.; Austrins, L. M.; Eimers, J.; O'Carroll, D. M.; Water Res. 2020, 183, 1.

74. Tsitonaki, A.; Petri, B.; Crimi, M.; Mosbæk, H.; Siegrist, R. L.; Bjerg, P. L.; Thompson, S.; Riggenbach, J.; Brown, R. A.; Hines, J.; Haselow, J.; Crit. Rev. Environ. Sci. Technol. 2010, 40, 55.

75. Mora, V. C.; Madueño, L.; Peluffo, M.; Rosso, J. A.; Del Panno, M. T. Morelli, I. S.; Environ. Sci. Pollut. Res. 2014, 21, 7548.

76. Pardo, F.; Santos, A.; Romero, A.; Sci. Total Environ. 2016, 566-567, 480.

77. Qiu, Y.; Xu, M.; Sun, Z.; Li, H.; Int. J. Environ. Res. Public Health 2019 , $16,441$.

78. Usman, M.; Faure, P.; Ruby, C.; Hanna, K.; Chemosphere 2012, 87, 234.

79. Li, J.; Yang, L.; Lai, B.; Liu, C.; He, Y.; Yao, G.; Li, N.; Chem. Eng. J. 2021, 414, 128674

80. Huang, D.; Wang, T.; Zhu, K.; Zhao, S.; Shi, Y.; Ye, M.; Wang, C.; Jia, H.; Chemosphere 2019, 225, 1 .

81. Ahmad, M.; Teel, A. L.; Watts, R. J.; J. Contam. Hydrol. 2010, 115, 34.

82. Química e mineralogia do solo; Melo, V. F., Alleoni, L. R. F., eds.; Sociedade Brasileira de Ciência do Solo: Viçosa, 2009.

83. Yen, C. H.; Chen, K. F.; Kao, C. M.; Liang, S. H.; Chen, T. Y.; J. Hazard. Mater. 2011, 186, 2097.

84. Usman, M.; Hanna, K.; Faure, P.; Sci. Total Environ. 2018, 634, 1100.

85. Song, Y.; Fang, G.; Zhu, C.; Zhu, F.; Wu, S.; Chen, N.; Wu, T.; Wang, Y.; Gao, J.; Zhou, D.; Chem. Eng. J. 2019, 335, 65

86. Cuypers, H.; Grotenhuis, T.; Joziasse, J.; Rulkens, W.; Environ. Sci. Technol. 2000, 34, 2057.

87. Mohammadi, F.; Alimohammadi, M.; Mahvi, A. H.; Nazmara, S.; Mazloomi, S.; Aslani, H.; Malaysian J. Soil Sci. 2016, 20, 67.

88. Gou, Y.; Zhao, Q.; Yang, S.; Wang, H.; Qiao, P.; Song, Y.; Cheng, Y.; Li, P.; Ecotoxicol. Environ. Saf. 2020, 190, 110092.

89. Medina, R.; David Gara, P. M.; Fernández-González, A. J.; Rosso, J. A.; Del Panno, M. T.; Sci. Total Environ. 2018, 618, 518 